\title{
Clinical outcomes of hospitalized Covid 19 pneumonia patients with and without metabolic syndrome.
}

\author{
Omer Ayten ${ }^{1}$, Inşa Gül Ekiz İscanlı ${ }^{1}$, Cengiz Özdemir ${ }^{2}$, Bengu Saylan ${ }^{1}$, Kadir Canoğlu ${ }^{1}$, \\ Tayfun Calişkan ${ }^{1}$, Celal Satıcı ${ }^{2}$, and Oğzuhan Okutan ${ }^{1}$ \\ ${ }^{1}$ Sultan Abdulhamid Han Egitim ve Arastirma Hastanesi \\ ${ }^{2}$ Yedikule Chest Diseases and Thoracic Surgery Training and Research Hospital
}

March 31, 2021

\begin{abstract}
Aims: Metabolic Syndrome has become the greatest health hazard in the modern world, along with infectious diseases. We aimed to evaluate the effects of metabolic syndrome on disease course, laboratory values and mortality in patients with COVID 19 pneumonia. Methods: COVID 19 pneumonia patients with and without metabolic syndrome were compared in terms of laboratory parameters, clinical results and mortality rates retrospectively. Results: A total of 194 patients hospitalized with COVID 19 pneumonia (with and without metabolic syndrome $\mathrm{n}=93$ and 101, respectively) were included in the study. Patients with metabolic syndrome had lower oxygen saturation at the time of admission (88.76 vs $93.66 \mathrm{p}<0.0001$ ), higher neutrophil ( 5.85 vs $4.81 \mathrm{p}=0.02)$ and CRP levels (88.36 vs $62.93 \mathrm{p}=0.009)$ and COVID 19 involvement was more common in lung tomography ( 12.3 vs $7.7 \mathrm{p}<0.0001)$. Total length of stay (12.3 vs 6.5 days p $<0.0001)$ and clinical length of stay (7.8 vs 5.9 days $\mathrm{p}=0.003)$ were longer in patients with metabolic syndrome. Requirement of intensive care $(45.2 \%$ vs $4.9 \% \mathrm{p}<0.0001)$ and mortality rates $(24.7 \%$ vs $0.9 \%$ p $<0.0001)$ were higher in patients with metabolic syndrome. Presence of metabolic syndrome (OR 32.86, 95\% CI 4.34 to $249 \mathrm{p}<0.05$ ) were significantly associated with increased mortality. Discussion and conclusion: Our results demonstrated that patients with metabolic syndrome that were hospitalized with COVID 19 pneumonia had significantly higher mortality and intensive care requirement. They have lower oxygen saturations, higher CRP levels and more widespread radiological involvement. Keywords: Covid 19 - Metabolic syndrome - Pneumonia - Mortality
\end{abstract}

\section{Cover Page}

Type of manuscript: Original article

Title: Clinical outcomes of hospitalized covid 19 pneumonia patients with and without metabolic syndrome.

Running Title: Metabolic syndrome and covid 19 pneumonia

Number of Tables: 3

Number of Figures: 1

Word Counts for Abstract: 247

Word Counts for The Text : 2178

Source of financial support in the form of grants: No

Conflict of interest : None declared

Author contributions : All authors read and approved the final version of the manuscript. O.A, I.G.E.I, C.O B.S. K.C, T.C, C.S and O.O planned the study. O.A, I.G.E.I, C.O, B.S, K.C, T.C, C.S and O.O 
collected data. O.A, I.G.E.I, C.O, B.S, K.C, T.C, C.S and O.O made the analysis of the data. O.A, I.G.E.I and C.O wrote the manuscript.

*Omer Ayten ${ }^{1}$. MD. Pulmonologist. Orcid number; 0000-0002-2275-4378

Insa G. Ekiz Iscanlı ${ }^{2}$. MD. Intensive Care Specialist. Orcid number; 0000-0003-0867-2015

Cengiz Ozdemir ${ }^{3}$. Associate Professor. Pulmonologist, Orcid number; 0000-0002-9816-8885

Bengü Saylan ${ }^{1}$.MD. Pulmonologist. Orcid number;0000-0002-5922-0847

Kadir Canoglu ${ }^{1}$. MD. Pulmonologist. Orcid number; 0000-0003-1579-3392

Tayfun Caliskan ${ }^{1}$. MD. Pulmonologist. Orcid number; 0000-0002-7905-2430

Celal Satici ${ }^{3}$. MD. Pulmonologist. Orcid number; 0000-0002-5457-9551

Oguzhan Okutan ${ }^{1}$. Professor. Pulmonologist. Orcid number; 0000-0002-4660-1595

${ }^{1}$ Sultan Abdulhamid Han Teaching Hospital, Department of Pulmonary Medicine, Istanbul, Turkey

${ }^{2}$ Sultan Abdulhamid Han Teaching Hospital, Department of Intensive Care Unit, Istanbul, Turkey

${ }^{3}$ Yedikule Teaching Hospital for Pulmonology and Thoracic Surgery, Department of Pulmonary Medicine, Istanbul, Turkey.

*Corresponding author : Omer AYTEN

Sultan Abdulhamid Han Teaching Hospital, Department of Pulmonary Medicine, Istanbul, Turkey

e-mail: omerayten2002@yahoo.com

Adress: Sultan Abdulhamid Han Teaching Hospital, Department of Pulmonary Medicine,, Selimiye Street, Tibbiye Avenue, Uskudar, Istanbul, Turkey

Post code: 34668 Phone: +905053695475

\section{Abstract}

Aims: Metabolic Syndrome has become the greatest health hazard in the modern world, along with infectious diseases. We aimed to evaluate the effects of metabolic syndrome on disease course, laboratory values and mortality in patients with COVID 19 pneumonia.

Methods: COVID 19 pneumonia patients with and without metabolic syndrome were compared in terms of laboratory parameters, clinical results and mortality rates retrospectively.

Results: A total of 194 patients hospitalized with COVID 19 pneumonia (with and without metabolic syndrome $\mathrm{n}=93$ and 101, respectively) were included in the study. Patients with metabolic syndrome had lower oxygen saturation at the time of admission (88.76 vs $93.66 \mathrm{p}<0.0001$ ), higher neutrophil (5.85 vs $4.81 \mathrm{p}=0.02)$ and CRP levels (88.36 vs $62.93 \mathrm{p}=0.009)$ and COVID 19 involvement was more common in lung tomography (12.3 vs $7.7 \mathrm{p}<0.0001)$. Total length of stay (12.3 vs 6.5 days $\mathrm{p}<0.0001)$ and clinical length of stay (7.8 vs 5.9 days $\mathrm{p}=0.003$ ) were longer in patients with metabolic syndrome. Requirement of intensive care $(45.2 \%$ vs $4.9 \% \mathrm{p}<0.0001)$ and mortality rates $(24.7 \%$ vs $0.9 \% \mathrm{p}<0.0001)$ were higher in patients with metabolic syndrome. Presence of metabolic syndrome (OR 32.86, 95\% CI 4.34 to 249 p <0.05) were significantly associated with increased mortality.

Discussion and conclusion: Our results demonstrated that patients with metabolic syndrome that were hospitalized with COVID 19 pneumonia had significantly higher mortality and intensive care requirement. They have lower oxygen saturations, higher CRP levels and more widespread radiological involvement.

Keywords: Covid 19 - Metabolic syndrome - Pneumonia - Mortality

What's already known about this topic? 
However, research has shown negative effects of obesity, hypertension and diabetes on mortality and morbidity in COVID 19 patients, studies conducted under the title of metabolic syndrome are limited.

\section{What does this article add?}

The results of the study show a very high mortality rate in COVID 19 pneumonia patients with metabolic syndrome, different from the two previously published studies.

\section{Introduction}

In December 2019, COVID-19, caused by a new coronavirus (SARS-CoV-2) turned into a pandemic affecting the entire world. By the end of December 2020, the number of people infected with SARS-CoV-2 exceeded 72 million and the number of COVID-19-related deaths exceeded 1.7 million worldwide. Most individuals (81\%) infected with SARS-CoV-2 are either asymptomatic or recovered with mild symptoms ${ }^{1}$. However, advanced age and comorbidities such as hypertension, diabetes, ischemic heart disease may lead to pneumonia, and acute respiratory distress symptom (ARDS), and the disease may progress more severely and mortally ${ }^{2,3}$. Metabolic syndrome is characterized by obesity, hypertension, hyperglycemia, and dyslipidemia. This new non-infectious disease has become the greatest health hazard in the modern world, along with infectious diseases. Today, more than 1 billion people worldwide are affected by metabolic syndrome ${ }^{4}$.

Metabolic syndrome is known to increase the risk of cardiovascular disease and diabetes mellitus, but it is still a matter of debate whether metabolic syndrome as a whole or its individual components increase this risk ${ }^{5}$. Hypertension and diabetes have been shown to increase mortality in COVID 19 patients, and obesity alone has been identified as an independent risk factor for the development of respiratory failure and increased mortality ${ }^{2,3,6}$. However research has shown negative effects of obesity, hypertension and diabetes on mortality and morbidity in COVID 19 patients, studies conducted under the title of metabolic syndrome are limited.

In our study, we aimed to evaluate the effects of metabolic syndrome on disease course, laboratory values and mortality in inpatients with COVID 19 pneumonia.

\section{Material and Methods}

\subsection{Definition}

Adult Treatment Panel III (ATP III) criteria were used for the definition of metabolic syndrome ${ }^{7}$. It is defined as the presence of three or more of the following factors:

1. Increased waist circumference ([?]102cm in men and [?] $88 \mathrm{~cm}$ in women, measured in the upright position),

2. Hypertriglyceridemia ( $>150 \mathrm{mg} / \mathrm{dL}$ or on treatment for hypertriglyceridemia),

3.Elevated blood pressure (systolic [?] 130 and / or diastolic [?] $85 \mathrm{~mm} \mathrm{Hg}$ or with a history of hypertension on treatment),

4. Reduced high-density lipoprotein cholesterol ( $<40 \mathrm{mg} / \mathrm{dL}$ in males; $<50 \mathrm{mg} / \mathrm{dL}$ in females),

5. Dysglycemia (100 mg / dL or on treatment for hyperglycemia).

\subsection{Study design and population}

In this retrospective cohort study, the data of 488 patients hospitalized with the diagnosis of COVID 19 pneumonia in a tertiary clinic between October 1, 2020 and November 20, 2020 were retrospectively analyzed in terms of metabolic syndrome criteria. Ethical approval of the study was obtained from Umraniye Training and Research Hospital Ethics Committee dated 20.01.2021 and numbered 1. Institutional approval was taken for the usage of the patient's data. Approval was obtained from all patients for the use of their data for the scientific article. Patients were hospitalized in the presence of at least one of the following criteria, in accordance with the COVID-19 guidelines of the Ministry of Health of Turkey ${ }^{8}$; 1 At room air, respiratory rate is [?] 24/min and SpO2 is [?] 93\%. 2. The presence of at least one of the following: Blood lymphocyte 
count of $<800 / \mu \mathrm{l}$, serum CRP $>10 \mathrm{x}$ upper limit of normal value, ferritin $>500 \mathrm{ng} / \mathrm{ml}$ and D-Dimer $>$ $1000 \mathrm{ng} / \mathrm{ml}$, 3. Having comorbidities such as arrhythmia, coronary artery disease, kidney disease. Inclusion criteria were as follows: Being older than 18 years of age, a positive COVID 19 PCR result, and having newonset infiltration in thorax computed tomography, compatible with COVID 19 pneumonia. SARS-CoV-2 was detected by next-generation sequencing or real-time RT-PCR method. Military patients who did not meet the hospitalization criteria and were followed up for the standard 14 days in isolation $(\mathrm{n}=79)$, patients with lack of data for metabolic syndrome $(\mathrm{n}=202)$ and patients whose standing waist circumference was not measured $(\mathrm{n}=13)$ were excluded from the study. A total of 194 patients were included. The patients were divided into two groups as patients with and without metabolic syndrome ( $\mathrm{n}=93$ and 101, respectively) (Figure 1).

\subsection{Data collection}

Demographic characteristics of the patients at the time of admission, standing waist circumference, height, weight, body mass index (BMI), comorbidities, oxygen saturations at room air $\left(\mathrm{SpO}_{2}\right)$, laboratory parameters (neutrophil, lymphocyte, neutrophil / lymphocyte ratio, lactate dehydrogenase (LDH), D-dimer, C-reactive protein (CRP), fasting blood glucose, high-density lipoprotein (HDL) cholesterol, total hospitalization periods, intensive care admission and mortality rates were recorded. Computed tomography was performed on all patients. The severity of the radiology findings was evaluated by scoring between 0-20 according to the degree of involvement of each lung lobe, as in the criteria set by Chang Y. and colleagues ${ }^{9}$. According to involvement of the disease, each of the 5 lobes was scored as:

.0 point $(0 \%)$,

. 1 point- Minimal (1-25\%),

. 2 points- Mild (26-50\%),

. 3 points- Moderate (51-75\%)

. 4 points- Severe $(76-100 \%)$.

Total radiological weight score was obtained by summing the scores of 5 lobes (0-20).

\subsection{Statistical analysis of data}

Parametric tests were used without performing normality test due to the compatibility of the Central Limit Theorem ${ }^{10}$. In the analysis of the data, mean and standard deviation, minimum and maximum values were used for continuous variables, and frequency and percentage were used when defining categorical variables. Student's t and Mann-Whitney U tests were performed to compare the means of two scale score groups. Chi-Square test was used to evaluate the relationship between categorical variables. The exposure ratio (odds ratio) was presented for variables thought to be associated with Metabolic Syndrome. Logistic regression analysis was used to investigate the association between mortality and metabolic syndrome. The statistical significance level was $\mathrm{p}<0.05$. Www.e-picos.com New York software and MedCalc statistics package program were used in assessing the data.

\section{Results}

A total of 194 patients hospitalized with a diagnosis of COVID 19 pneumonia were included in the study. The patients were divided into two groups as those with and without metabolic syndrome $(\mathrm{n}=93$ and 101, respectively). The mean age of the patients was $63.5 \pm 13.9$ years. The mean age of patients with metabolic syndrome was higher than that of patients without metabolic syndrome $(67.2 \pm 12.6$ vs $60.04 \pm$ 14.2 , respectively, $\mathrm{p}<0.0001)$. Metabolic syndrome patients had significantly higher median BMI $(67.2 \pm$ 12.6 vs $60.04 \pm 14, \mathrm{p}=0.001$ ) and waist circumference (in males: $103.26 \pm 13.57$ vs $91.75 \pm 10.27 \mathrm{p}<0.0001$, in females: $101.72 \pm 15.95$ vs $91.19 \pm 16.8 \mathrm{p}=0.004)$, non-fasting plasma glucose $(166.08 \pm 66.61$ vs 99.63 $\pm 30.12 \mathrm{p}<0.0001)$, triglyceride values $(170.21 \pm 85.91$ vs $108.67 \pm 37.74 \mathrm{p}<0.0001)$ and lower HDL levels (in males: $28.28 \pm 9.63$ vs $39.65 \pm 11.86 \mathrm{p}<0.0001$, in females: $34.48 \pm 12.85$ vs $49.17 \pm 12.02 \mathrm{p}<0.0001$ ). 
In patients with metabolic syndrome, hypertension ( $79.6 \%$ vs $17.8 \% \mathrm{p}<0.0001)$, diabetes mellitus (77.4\% vs $8.7 \% \mathrm{p}<0.0001)$, coronary artery disease $(30.1 \%$ vs $13.9 \% \mathrm{p}=0.006)$, and chronic obstructive pulmonary disease $(29 \%$ vs $16.8 \% \mathrm{p}=0.04)$ were more common. Patients with metabolic syndrome had lower oxygen saturation at the time of admission $(88.76 \pm 6.29$ vs $93.66 \pm 5.38 \mathrm{p}<0.0001)$ and more advanced infection was seen in the lung tomography $(12.3 \pm 4.1$ vs $7.7 \pm 3.4, \mathrm{p}<0.0001)$. Total length of stay $(12.3 \pm 6.8$ days vs $6.5 \pm 3.5$ days, $\mathrm{p}<0.0001)$ and clinical length of stay $(7.8 \pm 5.6$ days vs $5.9 \pm 2.4$ days $\mathrm{p}=0.003)$ were longer in patients with metabolic syndrome. Requirement of intensive care $(45.2 \%$ vs $4.9 \% \mathrm{p}<0.0001)$ and mortality rates $(24.7 \%$ vs $0.9 \%$ p $<0.0001)$ were higher in patients with metabolic syndrome. Table 1 shows demographics, baseline and clinical characteristics of patients with and without metabolic syndrome.

Neutrophil (5.85 \pm 3.49 vs $4.81 \pm 2.54 \mathrm{p}=0.02)$ and CRP levels $(88.36 \pm 64.84$ vs $62.93 \pm 68.58 \mathrm{p}=0.009)$ of patients with metabolic syndrome were higher compared to patients without metabolic syndrome at the time of admission $(\mathrm{p}<0.05)$. No significant difference was found between the two groups in terms of other prognostic laboratory factors such as LDH, lymphocyte count, N / L ratio and D-dimer levels ( $\mathrm{p}>0.05)$ (Table 2).

Presence of metabolic syndrome (OR 32.86, 95\% CI 4.34 to 249), age (OR 1.05, 95\% CI 1.01 to 1.08), CAD (OR 3.08, 95\% CI 1.25 to 7.56), hypertension (OR 6.81, 95\% CI 2.23 to 7.77), diabetes mellitus (OR 8.71, $95 \%$ CI 2.85 to 26.64 ), COPD (OR 2.86, $95 \%$ CI 1.17 to 6.99 ), CRP (OR $1.02,95 \%$ CI 1.01 to 1.04 ), radiological weight score (OR 1.28,95\% CI 1.14 to 1.44), total length of stay (OR 1.15, 95\% CI 1.07 to 1.23), ICU length of stay (OR 1.11, 95\% CI 1.01 to 1.24), hypertriglyceridemia (OR 1.02, 95\% CI 1.01 to 1.03) transfer to ICU (OR 139.92, 95\% CI 18.05 to 1884.83) were significantly associated with increased mortality $(\mathrm{p}<0.05)$ (Table 3$)$.

\section{Discussion}

The most striking finding of our study was that the presence of metabolic syndrome significantly increased mortality in patients with COVID 19 pneumonia. Among comorbid conditions in COVID 19 patients, the highest mortality rates were observed in CAD (10.5\%), diabetes mellitus (7.3\%), chronic respiratory diseases (6.3\%), hypertension $(6.0 \%)$ and cancer $(5.6 \%)$ patients $^{11}$. In a recent study conducted on black COVID 19 patients, the presence of metabolic syndrome was shown to increase mortality, the need for intensive care and mechanical ventilation, but the presence of comorbidities associated with metabolic syndrome, such as hypertension and diabetes alone, were not related with $i^{12}$. In another study involving 1870 patients, the presence of metabolic syndrome in COVID 19 patients increased mortality, the need for intensive care and mechanical ventilation. Among comorbidities associated with metabolic syndrome, diabetes was reported to increase mortality alone ${ }^{13}$. It is still unclear whether metabolic syndrome as a whole or its individual components increase this risk in COVID 19 patients. In our study, CAD, diabetes, hypertension, and hypertriglyceridemia were associated with increased mortality. However, metabolic syndrome was shown to increase mortality by 32.8 times. In addition, intensive care requirement and hospitalization were significantly higher in COVID 19 patients with metabolic syndrome.

In the literature, there are no studies regarding the effect of hypertriglyceridemia in COVID 19 patients, except in cases of hypertriglyceridemia secondary to tocilizumab, lopinavir and ritonavir therapy ${ }^{14}$. The mortality-increasing effect of hypertriglyceridemia found in our study may be parallel to the effect of coronary artery disease on mortality. In our study, since specific causes of death such as acute myocardial infarction and ischemic CV could not be verified, this finding could not be interpreted.

Although metabolic syndrome is more common in the elderly, mortality associated with metabolic syndrome decreases with age ${ }^{15,16}$. In many studies of COVID 19 patients, advanced age has been identified as the most important risk factor for increased mortality ${ }^{2,3,17,18}$. Similarly, in our study, the average age of patients with metabolic syndrome was higher and advanced age was associated with increased mortality.

Metabolic syndrome is one of the common comorbidities in patients with COPD. It is associated with physical inactivity and sedentary lifestyle, smoking and inflammatory cell activation in adipose tissue and lungs ${ }^{19,20}$. In many studies of COVID 19 patients, COPD has been identified as an independent risk factor 
that increases disease severity or mortality ${ }^{21,22,23}$. In our study, COPD was more frequent in COVID 19 patients with metabolic syndrome, and mortality rates were higher in patients with COPD.

The metabolic syndrome and aging is associated with a reduced cellular stress response that would make tissues more vulnerable to injury from Covid-19 increasing morbidity and mortality. Increased proinflammatory cytokines, such as IL- 6 and TNF- $\alpha$, in patients with metabolic syndrome are likely responsible for the development of diabetes, hypertension and coronary artery diseases, due to subclinical and persistent inflammation. This persistent inflammatory state causes an increase in acute phase reactants such as CRP, fibrinogen, and ferritin and is thought to worsen the clinical course of COVID 19 ${ }^{24,25}$. In our study, COVID 19 patients with metabolic syndrome had lower oxygen saturations, higher CRP levels and more widespread radiological involvement at presentation compared to those without metabolic syndrome. High CRP levels and radiological weight score were associated with increased mortality. The worse clinical, laboratory and radiological values at admission in COVID 19 patients with metabolic syndrome can be considered an indicator of the worsening of this constant and persistent inflammatory state with COVID 19 in the background.

The most important limitation of the study is that it is a retrospective study. Therefore, many patients had to be excluded because of lack of data for metabolic syndrome.

\section{Conclusion}

The most important finding of this study was the significantly higher mortality and intensive care requirement in metabolic syndrome patients hospitalized with COVID 19 pneumonia. Another important result was that COVID 19 patients with metabolic syndrome had lower oxygen saturations, higher CRP levels and more widespread radiological involvement at the time of admission, and that longer hospital follow-up was required in these patients. Presence of metabolic syndrome, CAD, hypertension, diabetes, COPD, increased CRP, radiological weight score, total length of stay, ICU length of stay, hypertriglyceridemia, and transfer to ICU were statistically associated with increased mortality.

\section{References}

1. WHO. Coronavirus disease (COVID-2019) situation reports. 2020. https://www.who.int/emergencies/diseases/novel-coronavirus-2019/situation-reports. Access on December 27, 2020.

2. Zhou F, Yu T, Du R, Fan G, Liu Y, Liu Z, et al. Clinical course and risk factors for mortality of adult inpatients with COVID-19 in Wuhan, China: a retrospective cohort study. Lancet. 2020;395:1054-1062

3. Ayten O, Saylan B. Retrospective analysis of severe COVID-19 pneumonia patients treated with lopinavir/ritonavir: A comparison with survivor and non-survivor patients. Southern African Journal of Infectious Diseases;2020; 35: 2312-0053 DOI: https://doi.org/10.4102/sajid.v35i1.233

4. Saklayen M.G, The Global Epidemic of the Metabolic Syndrome . Review Curr Hypertens Rep . 2018 Feb 26;20(2):12.

5. Hoffman E.L, Von Wald T, Hansen K. The metabolic syndrome . South Dakota Medicine. 2015; Spec No:24-8.

6. Rottoli M, Bernante P, Belvedere A, et al. Obesity is one of the strongest risk factor for respiratory failure and death in COVID-19. Patients: A Retrospective Multicentric Cohort Study, 2020

7. Grundy S.M, Cleeman J.I, Daniels S.R, Eckel R.H, Franklin B.A, Gordon D.J et al. Diagnosis and management of the metabolic syndrome: an American Heart Association/National Heart, Lung, and Blood Institute Scientific Statement. Circulation. 2005;112(17):2735-52.

8. COVID-19 (SARS-CoV-2 Infection) Guide of Ministry of Health of Republic of Turkey, April 14, 2020

9. Chang Y, Yu C, Chang S, Galvin JR, Liu H, Hsiao C, et al. Pulmonary sequelae in convalescent patients after severe acute respiratory syndrome: evaluation with thin-section CT. Radiology 2005;236(3):106775

10. Norman, G. (2010). Likert scales, levels of measurement and the "laws" of statistics. Advances in Health Sciences Education, 15 (5), 625-632

11. Wu Z, McGoogan JM. Characteristics of and important lessons from the coronavirus disease 2019 
(COVID-19) outbreak in China: summary of a report of 72,314 cases from the Chinese Center for Disease Control and Prevention. JAMA. 2020;323:1239-1242.

12. Xie J, Zu Y, Alkhatib A, Pham T.T, Gill F, Jang A et al. Metabolic Syndrome and COVID-19 Mortality Among Adult Black Patients in New Orleans. Diabetes Care. 2020 Aug 25;44(1):188-193.

13. Lohia P, Kapur S, Benjaram S, Pandey A, Mir T, Seyoum B. Metabolic Syndrome and clinical outcomes in patients infected with COVID19: Does age, sex and race of the patient with Metabolic Syndrome matter? J Diabetes. 2021 Jan 16. doi: 10.1111/1753-0407.13157. Online ahead of print.

14. Rubel A.A, Chong P.L, Abdullah M.S, Asli R, Momin R.N, Mani B.I et al. Lipemic serum in patients with Coronavirus Disease 2019 (COVID-19) undergoing treatment. J Med Virol. 2020 Jun 2 : 10.1002/ jmv. 25942. doi: 10.1002/jmv.25942 [Epub ahead of print]

15. Maggi S, Noale M, Gallina P, Bianchi D, Marzari C, Limongi F et al. The metabolic syndrome, incidence of diabetes and mortality among the elderly: The Italian Longitudinal Study of Aging. J Gerontol A Biol Sci Med Sci. 2006 May;61(5):505-10

16. Hildrum B, Mykletun A, Dahl AA, Midthjell K. Metabolic syndrome and risk of mortality in middleaged versus elderly individuals: the Nord-Trøndelag Health Study (HUNT). Diabetologia . 2009 Apr;52(4):583-90.

17. Li X, Xu S, Yu M, Wang K, Tao Y, Zhou Y et al. Risk factors for severity and mortality in adult COVID-19 inpatients in Wuhan. J Allergy Clin Immunol. 2020 Jul;146(1):110-118.

18. Albitar O, Ballouze R, Ooi J.P, Ghadzi S.M.S. Risk factors for mortality among COVID-19 patients. Diabetes Res Clin Pract. 2020 Aug;166:108293.

19. Wartz H, Waschki B, Kirsten A, Müller C, Kretschmar G, Meyer T at al . The Metabolic Syndrome in Patients With Chronic Bronchitis and COPD: Frequency and Associated Consequences for Systemic Inflammation and Physical Inactivity. Chest. 2009 October: 136; 4;1039-1046

20. Clini E, Crisafulli E, Radaeli A, Malerba M. COPD and the metabolic syndrome: an intriguing association Internal and Emergency Medicine 2013:8;283-289

21. Docherty AB, Harrison EM, Green CA, Hardwick HE, Pius R, Norman L, et al. ISARIC4C investigators. Features of 20133 UK patients in hospital with covid-19 using the ISARIC WHO clinical characterisation protocol: prospective observational cohort study. BMJ. 2020;369:m1985.

22. Grasselli G, Greco M, Zanella A, Albano G, Antonelli M, Bellani G, et al. COVID-19 Lombardy ICU Network. Risk factors associated with mortality among patients with COVID-19 in intensive care units in Lombardy, Italy. JAMA Intern Med. 2020;180:1345-1355.

23. Singh AK, Gillies CL, Singh R, Singh A, Chudasama Y, Coles B, et al. Prevalence of co-morbidities and their association with mortality in patients with COVID-19: a systematic review and meta-analysis Diabetes Obes Metab 2020 Jun 23 : 10.1111/dom.14124. doi: 10.1111/dom.14124 [Epub ahead of print]

24. Nakajima K. Serious Conditions in COVID-19 Accompanied With a Feature of Metabolic Syndrome. J Clin Med Res. 2020 May; 12(5): 273-275.Leisegang K, Henkel R, Agarwal A. Obesity and metabolic syndrome associated with systemic inflammation and the impact on the male reproductive system. Am J Reprod Immunol. 2019;82(5):e13178

25. Chocair P.R, Neves P.D.M.M, Pereira L.V.B, Mohrbacher S, Oliveira E.S, Nardotto L.L et al. Covid-19 and Metabolic Syndrome . Letters to editor. Rev Assoc Med Bras. 2020; 66(7):871-875

Figure 1. Study design and population

\begin{tabular}{|c|c|c|c|c|c|}
\hline Variables & & 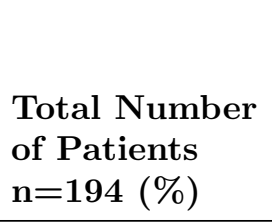 & $\begin{array}{l}\text { Metabolic } \\
\text { Syndrome } \\
\text { Patients } \mathrm{n}=93 \\
(\%)\end{array}$ & $\begin{array}{l}\text { Non - } \\
\text { Metabolic } \\
\text { Syndrome } \\
\text { Patients } \\
\text { n=101 (\%) }\end{array}$ & $\mathrm{p}$ \\
\hline \multirow[t]{2}{*}{ Gender } & Male & $110(56,7)$ & $50(53,8)$ & $60(59,4)$ & $0,43^{*}$ \\
\hline & Female & $84(43,3)$ & $43(46,2)$ & $41(40,6)$ & \\
\hline Age & $\begin{array}{l}\text { Mean }(\mathrm{SD}) \\
\text { (years) }\end{array}$ & $63,5 \pm 13,9$ & $67,2 \pm 12,6$ & $60,04 \pm 14,2$ & $<0,0001$ \\
\hline
\end{tabular}




\begin{tabular}{|c|c|c|c|c|c|}
\hline Variables & & $\begin{array}{l}\text { Total Number } \\
\text { of Patients } \\
\mathrm{n}=194(\%)\end{array}$ & $\begin{array}{l}\text { Metabolic } \\
\text { Syndrome } \\
\text { Patients } n=93 \\
(\%)\end{array}$ & $\begin{array}{l}\text { Non - } \\
\text { Metabolic } \\
\text { Syndrome } \\
\text { Patients } \\
\text { n=101 (\%) }\end{array}$ & $\mathbf{p}$ \\
\hline $\begin{array}{l}\mathrm{BMI} \\
\left(\mathrm{kg} / \mathrm{m}^{2}\right)\end{array}$ & Mean (SD) & $28,73 \pm 4,95$ & $29,99 \pm 5,28$ & $27,56 \pm 4,34$ & $0,001 * *$ \\
\hline \multirow[t]{2}{*}{ Smoking } & Yes & $61(31,4)$ & $34(36,6)$ & $27(26,7)$ & $0,14^{*}$ \\
\hline & No & $133(68,6)$ & $59(63,4)$ & $74(73,3)$ & \\
\hline \multirow[t]{2}{*}{ Comorbidities } & Yes & $144(74,2)$ & $88(94,6)$ & $56(55,4)$ & $<0,0001^{*}$ \\
\hline & No & $50(25,8)$ & $5(5,4)$ & $45(44,6)$ & \\
\hline \multirow[t]{2}{*}{ Hypertension } & Yes & $92(47,4)$ & $74(79,6)$ & $18(17,8)$ & $<0,0001^{*}$ \\
\hline & No & $102(52,6)$ & $19(10,4)$ & $83(82,2)$ & \\
\hline \multirow[t]{2}{*}{ Diabetes } & Yes & $82(42,3)$ & $72(77,4)$ & $10(9,9)$ & $<0,0001^{*}$ \\
\hline & No & $112(57,7)$ & $21(22,6)$ & $91(90.1)$ & \\
\hline \multirow[t]{2}{*}{ Arrhythmia } & Yes & $12(6,2)$ & $8(8,6)$ & $4(3,9)$ & $0,18^{*}$ \\
\hline & No & $184(93,8)$ & $85(91,4)$ & $97(96,1)$ & \\
\hline \multirow[t]{2}{*}{ CAD } & Yes & $42(21,6)$ & $28(30,1)$ & $14(13,9)$ & $0,006^{*}$ \\
\hline & No & $152(78,4)$ & $65(69,9)$ & $87(86,1)$ & \\
\hline \multirow[t]{2}{*}{$\mathrm{CHF}$} & Yes & $15(7,7)$ & $10(10,8)$ & $5(4,9)$ & $0,13^{*}$ \\
\hline & No & $179(92,3)$ & $83(89,2)$ & $96(95,1)$ & \\
\hline \multirow[t]{2}{*}{ COPD } & Yes & $44(22,7)$ & $27(29)$ & $17(16,8)$ & $0,04^{*}$ \\
\hline & No & $150(77,3)$ & $66(71)$ & $84(83,2)$ & \\
\hline \multirow[t]{2}{*}{ Malignancy } & Yes & $19(9,8)$ & $10(10,8)$ & $9(8,9)$ & $0,67^{*}$ \\
\hline & No & $175(90,2)$ & $83(89,2)$ & $92(91,1)$ & \\
\hline \multicolumn{2}{|c|}{ Immunosuppression Yes } & $6(3,1)$ & $3(3,2)$ & $3(2,9)$ & $0,92^{*}$ \\
\hline & No & $188(96,9)$ & $90(96,8)$ & $98(97,1)$ & \\
\hline \multirow{2}{*}{$\begin{array}{l}\text { Waist cir- } \\
\text { cumference }\end{array}$} & Male & $96,98 \pm 13,15$ & $103,26 \pm 13,57$ & $91,75 \pm 10,27$ & $<0,0001 * *$ \\
\hline & Female & $96,58 \pm 17,11$ & $101,72 \pm 15,95$ & $91,19 \pm 16,8$ & $0,004^{* *}$ \\
\hline \multirow[t]{2}{*}{ HDL levels } & Male & $34,48 \pm 12,24$ & $28,28 \pm 9,63$ & $39,65 \pm 11,86$ & $<0,0001^{* *}$ \\
\hline & Female & $41,65 \pm 14,41$ & $34,48 \pm 12,85$ & $49,17 \pm 12,02$ & $<0,0001^{* *}$ \\
\hline $\begin{array}{l}\text { Non-fasting } \\
\text { plasma glucose } \\
\text { levels }\end{array}$ & Mean (SD) & $131,48 \pm 60,76$ & $166,08 \pm 66,61$ & $99,63 \pm 30,12$ & $<0,0001^{* *}$ \\
\hline $\begin{array}{l}\text { Triglyceride } \\
\text { levels }\end{array}$ & Mean (SD) & $138,17 \pm 72,15$ & $170,21 \pm 85,91$ & $108,67 \pm 37,74$ & $<0,0001^{* *}$ \\
\hline SpO2 levels & Mean (SD) & $91,34 \pm 6,32$ & $88,76 \pm 6,29$ & $93,66 \pm 5,38$ & $<0,0001^{* *}$ \\
\hline $\begin{array}{l}\text { Radiological } \\
\text { weight score }\end{array}$ & Mean (SD) & $9,9 \pm 4,4$ & $12,3 \pm 4,1$ & $7,7 \pm 3,4$ & $<0,0001 * * *$ \\
\hline $\begin{array}{l}\text { Total Length } \\
\text { of Stay (day) }\end{array}$ & Mean (SD) & $9,2 \pm 6,1$ & $12,3 \pm 6,8$ & $6,5 \pm 3,5$ & $<0,0001^{* *}$ \\
\hline \multicolumn{6}{|l|}{$\begin{array}{l}\text { Length of Stay } \\
\text { (day) }\end{array}$} \\
\hline $\begin{array}{l}\text { ICU Length of } \\
\text { Stay (day) }\end{array}$ & Mean (SD) & $10,1 \pm 6,6$ & $10 \pm 6,8$ & $11 \pm 5,9$ & $0,76^{* *}$ \\
\hline \multirow{2}{*}{$\begin{array}{l}\text { Stay (day) } \\
\text { Transfer to } \\
\text { ICU }\end{array}$} & Yes & $47(24,2)$ & $42(45,2)$ & $5(4,9)$ & $<0,0001^{*}$ \\
\hline & No & $147(75,8)$ & $51(54,8)$ & $96(95,1)$ & \\
\hline Death & Yes & $24(12,4)$ & $23(24,7)$ & $1(0,9)$ & $<0,0001^{*}$ \\
\hline
\end{tabular}




\begin{tabular}{|c|c|c|c|c|}
\hline Variables & $\begin{array}{l}\text { Total Number } \\
\text { of Patients } \\
\mathrm{n}=194(\%)\end{array}$ & $\begin{array}{l}\text { Metabolic } \\
\text { Syndrome } \\
\text { Patients } \mathrm{n}=93 \\
(\%)\end{array}$ & $\begin{array}{l}\text { Non - } \\
\text { Metabolic } \\
\text { Syndrome } \\
\text { Patients } \\
\text { n=101 (\%) }\end{array}$ & $\mathbf{p}$ \\
\hline No & $170(87,6)$ & $70(75,3)$ & $100(99,1)$ & \\
\hline
\end{tabular}

Table 1. Demographics, baseline and clinical characteristics of patients

${ }^{*} \mathrm{p}$ is significant at the level of $<0.05$. ( ${ }^{*}$ Chi-square test, ${ }^{* *}$ Student's $\mathrm{t}$ - test, ${ }^{* * *}$ Mann-Whitney U test )

Abbreviations: N, number; SD, standard deviation; BMI, body mass index; CAD, coronary artery disease; CHF, congestive heart failure; COPD, chronic obstructive pulmonary disease; HDL, high density lipoprotein; ICU, intensive care unit.

Table 2. Comparison of laboratory parameters of patients at admistiration

\begin{tabular}{|c|c|c|c|c|}
\hline Variables & $\begin{array}{l}\text { Total Number of } \\
\text { Patients } n=194 \\
(x \pm \text { SD) }\end{array}$ & $\begin{array}{l}\text { Metabolic } \\
\text { Syndrome } \\
\text { Patients } \mathrm{n}=93 \\
\mathrm{x} \pm \mathrm{SD}\end{array}$ & $\begin{array}{l}\text { Non - Metabolic } \\
\text { Syndrome } \\
\text { Patients } n=101 \\
x \pm \text { SD }\end{array}$ & $\mathrm{p}^{*}$ \\
\hline $\begin{array}{l}\text { Lymphocyte } \\
\left(\mathrm{K} / \mathrm{mm}^{3}\right)\end{array}$ & $1,86 \pm 6,3$ & $2,42 \pm 9,08$ & $1,35 \pm 0,72$ & 0,24 \\
\hline $\begin{array}{l}\text { Neutrophil } \\
\left(\mathrm{K} / \mathrm{mm}^{3}\right)\end{array}$ & $5,31 \pm 3,07$ & $5,85 \pm 3,49$ & $4,81 \pm 2,54$ & 0,02 \\
\hline $\mathrm{N} / \mathrm{L}$ ratio & $5,11 \pm 4,09$ & $5,6 \pm 4,34$ & $4,65 \pm 3,81$ & 0,11 \\
\hline CRP (mg/L) & $75,12 \pm 67,84$ & $88,36 \pm 64,84$ & $62,93 \pm 68,58$ & 0,009 \\
\hline LDH $(\mathbf{U} / \mathbf{L})$ & $555,77 \pm 366,27$ & $571,25 \pm 220,66$ & $541,52 \pm 462,28$ & 0,57 \\
\hline $\begin{array}{l}\Delta-\Delta \mu \varepsilon_{\rho} \rho \\
\left(\mu_{\gamma} / \Lambda\right)\end{array}$ & $1258,23 \pm 1850,54$ & $1259,58 \pm 1622,65$ & $1256,99 \pm 2046,21$ & 0,99 \\
\hline
\end{tabular}

${ }^{*} \mathrm{p}$ is significant at the level of $<0.05$. (*Student's t-test)

Abbreviations: N, number; SD, standard deviation; N/L, neutrophil lymphocyte ratio; CRP, C-reactive protein; LDH, lactate dehydrogenase

Table 3. Factors related with mortality in all patients

\begin{tabular}{lllll}
\hline Variables & Odds Ratio & Lower $\mathbf{( \% 9 5 ~ C I ) ~}$ & Upper (\%95 CI) & p $^{*}$ \\
\hline Metabolic Syndrome & 32,86 & 4,34 & 249 & $<0,05$ \\
Age & 1,05 & 1,01 & 1,08 & $<0,05$ \\
CAD & 3,08 & 1,25 & 7,56 & $<0,05$ \\
Hypertension & 6,81 & 2,23 & 20,77 & $<0,05$ \\
Diabetes & 8,71 & 2,85 & 26,64 & $<0,05$ \\
COPD & 2,86 & 1,17 & 6,99 & $<0,05$ \\
CRP & 1,02 & 1,01 & 1,04 & $<0,05$ \\
Radiological weight score & 1,28 & 1,14 & 1,44 & $<0,05$ \\
Total Length of Stay & 1,15 & 1,07 & 1,23 & $<0,05$ \\
Transfer to ICU & 139,92 & 18,05 & 1084,83 & $<0,05$
\end{tabular}




\begin{tabular}{lllll}
\hline Variables & Odds Ratio & Lower (\%95 CI) & Upper (\%95 CI) & p* $^{*}$ \\
\hline ICU Length of Stay & 1,11 & 1,01 & 1,24 & $<0,05$ \\
Hypertriglyceridemia & 1,02 & 1,01 & 1,03 & $<0,05$ \\
\hline
\end{tabular}

${ }^{*} \mathrm{p}$ is significant at the level of $<0.05$. (Odds ratio)

Abbreviations: CAD, coronary artery disease; COPD, chronic obstructive pulmonary disease; CRP, C-reactive protein;

ICU, intensive care unit.

Hosted file

Figure 1. Study design and population.pdf available at https://authorea.com/users/405020/ articles/516090-clinical-outcomes-of-hospitalized-covid-19-pneumonia-patients-with-andwithout-metabolic-syndrome 